\title{
Potencial agronômico e divergência genética entre genótipos de feijão-vagem de crescimento determinado
}

\section{Agronomic potential and genetic divergence among genotypes of bush snap bean}

\author{
Rosângela Maria Pinto Moreira ${ }^{1 *}$; Josué Maldonado Ferreira ${ }^{1}$; \\ Lúcia Sadayo Assari Takahashi²; Maria Elizabeth Costa Vanconcelos ${ }^{3}$; \\ Leonardo Cornélio Geus ${ }^{4}$; Leandro Botti ${ }^{4}$
}

\section{Resumo}

O objetivo deste estudo foi avaliar 11 linhagens e três cultivares de feijão-vagem de crescimento determinado, quanto a divergência genética e o potencial agronômico nas condições de Londrina e Cambé, Paraná, Brasil. O experimento foi em blocos ao acaso, com três repetições, e parcelas constituídas por quatro fileiras com 4,0m de comprimento e $0,5 \mathrm{~m}$ entre fileiras. Oito caracteres foram avaliados e submetidos às análises de variância individual, conjunta e multivariada. Houve diferenças significativas entre os genótipos para as características consideradas. A interação genótipo $\mathrm{x}$ locais não foi significativa para produção e diâmetro de vagem, revelando um desempenho consistente destas características e dos genótipos nestes locais. A divergência genética observada entre os genótipos de feijão-vagem foi quantificada pelos três primeiros componentes principais e três primeiras variáveis canônicas que explicaram $90,2 \%$ e $88,7 \%$ da variação total disponível, respectivamente. As características morfológicas de vagens e produção de sementes foram agrupadas nos dois primeiros componentes e as características relacionadas à produção de vagens foram agrupadas no terceiro componente, para a análise de componentes principais. Os dendrogramas, baseados nas distâncias euclidianas a partir dos escores dos três principais componentes principais e variáveis canônicas, separaram os genótipos em cinco e sete grupos respectivamente. As cultivares ficaram representadas em diferentes agrupamentos. As linhagens mais promissoras, HAB 402, HAB 415 e HAB 417, pertencem ao mesmo grupo e são dissimilares em relação às cultivares testadas.

Palavras-chave: Phaseolus vulgaris L, dissimilaridade genética, germoplasma, análise multivariada, seleção de genótipo

\footnotetext{
Abstract

The aim of this study was to evaluate 11 breeding lines and three bush snap bean cultivars related to genetic divergence and agronomic potential in Londrina and Cambé, Paraná, Brazil. The experimental design was a randomized complete block with three replications. Each plot was represented by four rows of $4.0 \mathrm{~m}$ long with $0.5 \mathrm{~m}$ between rows. Eight characters were evaluated and submitted to individual and joint analysis of variance and multivariate analysis. There were statistical differences among genotypes for all the studied characteristics. The interaction genotype $\mathrm{x}$ local was not significant for

1 Professores Doutores do Departamento de Biologia Geral/ CCB, Universidade Estadual de Londrina, CP 6001 CEP 86051-990 Londrina (PR) E-mail: rosang@uel.br; josuemf@uel.br

2 Professora Doutora do Departamento de Agronomia/ CCA, Universidade Estadual de Londrina, CP 6001 CEP 86051-990 Londrina (PR). E-mail: sadayo@uel.br

3 Pesquisadora do Instituto Agronômico do Paraná, Rodovia Celso Garcia Cid, km 375, E-Mail: bethvasc@pr.gov.br

4 UEL, ex-Alunos do Curso de Agronomia da Universidade Estadual de Londrina.

Autor para correspondência
} 
production and pod diameter, showing a consistent performance of these characteristics and genotypes at these locations. The genetic divergence observed among genotypes was quantified within the first three principal components and the first three canonical variables that explained $90.2 \%$ and $88.7 \%$ of the total variation available, respectively. The morphologic characteristics and the seed production were within the first and second components and the snap bean production characteristics were within the third principal component. Five and seven groups of dissimilarity were defined of the principal components and canonical variables, respectively. The cultivars were represented in different groups. The most promising lines HAB 402, HAB 415, HAB 417 belong to the same group and are dissimilar in relation to the tested cultivars.

Key words: Phaseolus vulgaris L, genetic dissimilarity, germplasm, multivariate analysis, selection of genotypes

\section{Introdução}

O feijão-vagem (Phaseolus vulgaris L.) pertence à família das leguminosas, sendo a mesma espécie botânica do feijão para grãos secos. A característica principal que distingue o feijão-vagem dos outros feijões é que a vagem constitui a parte comestível, com todo seu conteúdo. Uma boa cultivar desta hortaliça deve ser vigorosa e produtiva; apresentar razoável resistência às doenças e pragas; produzir vagens de cor verde-clara, com forma e dimensões que satisfaçam às exigências do mercado; possuir sabor agradável e ser desprovida, ao máximo, de fios ou fibras (CASTELLANE; VIEIRA; CARVALHO, 1988; BLANCO; CROPPO; TESSARIOLI NETO, 1997), constituindo-se uma boa fonte de proteína para a nutrição humana.

No Brasil, as principais cultivares de feijãovagem recomendados são os de crescimento indeterminado que atingem maiores produções, necessitam de cuidados mais intensos em relação à condução da cultura, possuem grande exigência em mão de obra, já que necessitam de tutoramento e por ter ciclo maior são mais sujeitas a ataques de pragas e doenças, aumentando assim os custos de produção (BRANDÃO, 2001). Por outro lado, as cultivares de crescimentodeterminado apresentamoflorescimento em um breve período de tempo, permitindo concentrar a produção. O ciclo menor racionaliza o uso do solo e de mão de obra, contribuindo para facilitar o cultivo e, principalmente, a redução de custos, aumentando a renda do produtor de vagens. Outra vantagem é a possibilidade de se efetuar uma única colheita, arrancando as plantas no campo e posteriormente separando as vagens (PEIXOTO et al., 1993; PEIXOTO et al., 1997; FILGUEIRA, 2003). O reduzido ciclo da cultura e a possibilidade de mecanização total, da semeadura à colheita, constituem um excelente atrativo.

A produção de sementes de feijão-vagem em si não depende de tecnologias complexas ou muito caras. Talvez o ponto crítico da cultura esteja no desenvolvimento de cultivares mais resistentes a fatores ambientais adversos, sem que isso altere o valor comercial. Há vários problemas a serem resolvidos para aumentar a produtividade e a qualidade do feijão-vagem: falta de cultivares com boa adaptabilidade às condições ambientais, suscetibilidade das cultivares às doenças, necessidade de sementes com boa qualidade, etc. Um dos meios para se obter significativo avanços neste sentido, envolvem investimentos no melhoramento genético desta cultura, utilizandose de introdução de germoplasmas, hibridação, métodos de melhoramento e uso de métodos de avaliação e seleção.

$\mathrm{Na}$ busca por cultivares superiores, a utilização da variabilidade genética nos cruzamentos de grupos geneticamente divergentes representa uma importante estratégia para obter ganhos seleção. A utilização de técnicas multivariadas é uma opção viável para esta finalidade, uma vez que permite múltiplas combinações de informações dentro da unidade experimental, através da discriminação do genótipo com base em uma variável complexa. 
A importância da diversidade genética para o melhoramento reside no fato de fornecerem parâmetros para a identificação de genitores que, quando cruzados, possibilitariam maior efeito heterótico na progênie e maior probabilidade de recuperar genótipos superiores nas gerações segregantes (CRUZ; REGAZZI, 2001).

As técnicas de análises multivariadas baseadas nas múltiplas informações fenotípicas, relacionando as diferenças fisiológicas, morfológicas, agronômicas e moleculares em feijão-vagem, foram utilizadas por Maluf e Ferreira (1983), Rodrigues et al. (1998), Fonseca e Silva (1999), Peixoto et al. (2002), Emygdio et al, (2003), Teixeira et al. (2004), Abreu et al, (2004), Silva et al. (2005).

Dentre as técnicas de análise multivariada temse a análise por componentes principais, variáveis canônicas e de agrupamento. A análise por componentes principais consiste em transformar um conjunto original de variáveis (por exemplo: altura, produção, etc) em outro conjunto de dimensão equivalente, mas com propriedades importantes, que são de grande interesse em certos estudos de melhoramento. Cada componente principal é uma combinação linear das variáveis originais. Além disso, são independentes entre si e estimados com o propósito de reter, em ordem de estimação, o máximo da informação, em termos de variação total, contida nos dados iniciais (CRUZ; REGAZZI, 2001). Além de possibilitar o estudo da diversidade genética de um grupo de genitores, a técnica dos componentes principais tem a vantagem de possibilitar a avaliação da importância de cada caráter estudado sobre a variação total disponível entre os genótipos avaliados. Esta avaliação possibilita o descarte de caracteres que contribuem pouco para a discriminação do material avaliado, reduzindo, desta forma, mão-de-obra, tempo e custo despendidos na experimentação agrícola (IEZZONI; PRITTS, 1991). As variáveis canônicas, por sua vez, assemelham-se aos componentes principais, porém com a vantagem adicional de levar em consideração tanto a matriz de covariância residual quanto a de covariância fenotípica entre os caracteres avaliados, necessitando que as avaliações tenham repetições (CRUZ; REGAZZI, 2001).

A análise de agrupamento tem por finalidade reunir, por algum critério de classificação, as variedades (ou qualquer outro tipo de unidade amostral) em vários grupos, de tal forma que exista homogeneidade dentro do grupo e heterogeneidade entre grupos. Alternativamente, as técnicas de análise de agrupamento têm por objetivo, ainda, dividir um grupo original de observações em vários grupos, segundo algum critério de similaridade ou dissimilaridade (CRUZ ; REGAZZI, 2001).

A disponibilidade de genótipos adaptados às condições edafoclimáticas regionais depende da caracterização, identificação e seleção de genótipos com potencial para o cultivo e melhoramento, visando o aumento do rendimento e da qualidade do feijão-vagem. Este trabalho teve por objetivos: avaliar o desempenho agronômico de 11 linhagens e três cultivares de feijão-vagem de crescimento determinado na Região de Londrina, Paraná; estimar a divergência genética destas linhagens em relação às três cultivares; fazer uma seleção de genótipos adaptados à região e avaliar a concordância de estimativas de divergência genéticas, obtidas por componentes principais e variáveis canônicas.

\section{Material e métodos}

Os experimentos foram conduzidos em dois locais com solos do tipo Cfa, Latossolo Roxo (Oxisol) de textura argilosa, eutrófico (CORREIA; GODOI; BERNANRDES, 1982): Fazenda Escola da Universidade Estadual de Londrina (latitude $23^{\circ}$ $23^{\prime} 00^{\prime}$ S, longitude $51^{\circ} 11^{\prime} 00^{\prime}$ " W e altitude de 560 $\mathrm{m})$ em novembro de 2004 e no município de Cambé, (latitude $23^{\circ} 16^{\prime} 33^{\prime \prime} \mathrm{S}$, longitude $51^{\circ} 16^{\prime} 42^{\prime \prime} \mathrm{W}$ e altitude de $595 \mathrm{~m}$ ), em propriedade de agricultor, em outubro de 2004, objetivando seleção de novos genótipos para o período de verão. 
$\mathrm{Na}$ semeadura dos dois experimentos, foi realizada uma adubação, aplicando-se 16, 56 e $32 \mathrm{~kg}$ ha $^{-1}$ de $\mathrm{N}, \mathrm{P}_{2} \mathrm{O}_{5}$ e $\mathrm{K}_{2} \mathrm{O}$ respectivamente (formulação 08-28-16). O controle de plantas daninhas foi feito por meio de capinas quando necessário.

O delineamento experimental utilizado foi o de blocos ao acaso com três repetições, em parcelas de quatro fileiras no espaçamento de 4,00 x 0,50 m, com densidade de 12 sementes por metro. Padronizou-se a utilização de duas fileiras adjacentes, à esquerda, para avaliar características da vagem e duas fileiras adjacentes, à direita, para avaliar produção de sementes. Os genótipos utilizados foram: 11 linhagens introduzidas da Embrapa - Arroz e Feijão (Linhagens HAB 402, HAB 415, HAB 417, HAB 429, НАВ 430, НАВ 431, НАB 441, НАB 444, HAB 447, HAB 448 e HAB 449) e três cultivares comerciais (Novirex, UEL 2 e Coralina). A escolha desses genótipos foi baseada em dados disponíveis na literatura e observações realizadas a campo (PEIXOTO et al., 1997; ATHANÁZIO et al., 1998; PINTO et al., 2001; SILVA et al., 2001), relativos a diversos caracteres agronômicos de interesse, avaliados em sistema tradicional de cultivo.

As características avaliadas foram: número médio de vagens por planta (NV), obtido pela razão entre o número total de vagens e o número de plantas da parcela; comprimento de vagem ( $\mathrm{CV}$, em $\mathrm{cm})$, obtido pela média do comprimento de 10 vagens por parcela; diâmetro de vagem (DV, em mm), obtido pela média de 10 vagens por parcela, medindo-se na sua parte mediana; largura de vagem (LV, em $\mathrm{cm}$ ), obtida pela media da largura transversal de 10 vagens por parcela; produção de vagem $(\mathrm{PV}$, em $\mathrm{t}$ $\left.\mathrm{ha}^{-1}\right)$; produção de sementes (PS, em $\mathrm{kg} \mathrm{ha}^{-1}$ ), com umidade das sementes em 13\%; número médio de sementes por vagem (NS), obtido em 50 vagens por parcela e porcentagem de casca na vagem seca (PC, em \%). As características PV e PS foram corrigidas para estande ideal, segundo Vencovsky e Barriga (1992). As estimativas de médias foram comparadas, entre as linhagens e cultivares, utilizando o teste de Scott-Knott, em nível de significância de 5\% de probabilidade. Os dados foram analisados através de métodos estatísticos uni e multivariados utilizandose o Programa Genes (CRUZ, 2006).

Para análise multivariada, calculou-se a matriz de correlação, covariância residual e fenotípica entre os oito caracteres quantitativos avaliados em Londrina, para as 11 linhagens e três cultivares de feijão-vagem. Baseando-se nessas matrizes, fezse a análise de componentes principais e variáveis canônicas, obtendo os escores entre os genótipos. Com os escores dos três componentes principais e três variáveis canônicas, calculou-se a medida de dissimilaridade baseada na distância Euclidiana, e utilizou-se o método hierárquico aglomerativo de ligação média entre grupos para realizar o agrupamento dos genótipos de comportamento semelhante, formando conjuntos homogêneos.

\section{Resultados e discussão}

Houve diferenças significativas entre as médias dos genótipos, em nível de 5 e 1\% de probabilidade pelo teste $\mathrm{F}$, para todas as características em Londrina, para produção de vagens em Cambé e para produção, comprimento e diâmetro de vagens na análise conjunta, o que indica a existência de diferenças entre os genótipos de feijão-vagem. A interação genótipo x locais não foi significativa para produção e diâmetro de vagem, revelando um desempenho consistente, destas características, dos genótipos nestes locais (Tabela 1). 
Tabela 1. Quadrados médios e níveis de significância das análises de variância individuais e conjunta, para produção de vagem $\left(\mathrm{PV}\right.$, em t ha $\left.{ }^{-1}\right)$, número de vagens por planta $(\mathrm{NV})$, comprimento de vagem $(\mathrm{CV}$, em $\mathrm{cm})$, diâmetro de vagem (DV, em mm), e da análise de variância individual em Londrina para largura de vagem ( $\mathrm{LV}$, em $\mathrm{cm})$, número médio de sementes por vagem (NS), produção de sementes (PS, em kg ha-1) e porcentagem de casca na vagem seca (PC, em \%) obtidas para 11 linhagens HAB e três cultivares de feijão-vagem cultivados em Londrina e Cambé (PR).

\begin{tabular}{|c|c|c|c|c|c|c|c|c|c|}
\hline \multirow[b]{2}{*}{ F.V. } & \multicolumn{9}{|c|}{ QM da análise individual - Londrina } \\
\hline & GL & $\mathrm{PV}$ & NV & $\mathrm{CV}$ & DV & LV & NS & $\mathrm{PS}^{1}$ & $\mathrm{PC}$ \\
\hline Blocos & 2 & 5,38 & 2,12 & 1,31 & 1,67 & 1,27 & 0,34 & 17,7 & 10,5 \\
\hline Genótipos (G) & 13 & $4,83 *$ & $4,72 * *$ & $3,55^{* *}$ & $1,64 * *$ & $2,46 * *$ & $1,15^{* *}$ & $45,9 * *$ & $63,1 * *$ \\
\hline \multirow[t]{2}{*}{ Resíduo } & 26 & 2,10 & 1,10 & 0,84 & 0,57 & 0,40 & 0,14 & 12,6 & 9,06 \\
\hline & \multicolumn{9}{|c|}{ QM da análise individual - Cambé } \\
\hline F.V. & GL & & $\mathrm{PV}$ & & NV & & $\mathrm{CV}$ & & DV \\
\hline Blocos & 2 & & 25,5 & & 1,20 & & 0,34 & & 1,37 \\
\hline Genótipos (G) & 13 & & $8,52 *$ & & $1,43^{\mathrm{ns}}$ & & $10,4^{\mathrm{ns}}$ & & $4,54^{\mathrm{ns}}$ \\
\hline \multirow[t]{2}{*}{ Resíduo } & 26 & & 3,18 & & 26,2 & & 10,3 & & 0,61 \\
\hline & \multicolumn{9}{|c|}{ QM da análise conjunta } \\
\hline F.V. & GL & & $\mathrm{PV}$ & & $\mathrm{NV}$ & & $\mathrm{CV}$ & & DV \\
\hline Blocos/Local & 4 & & 15,43 & & 1,663 & & 0,822 & & 1,521 \\
\hline Genótipos $(\mathrm{G})$ & 13 & & $9,906^{*}$ & & $3,727^{\mathrm{ns}}$ & & $11,80^{* *}$ & & $5,104 * *$ \\
\hline Locais (L) & 1 & & $64,89^{\text {ns }}$ & & $147,4 * *$ & & $111,1 * *$ & & $643,3 * *$ \\
\hline $\mathrm{G} \times \mathrm{L}$ & 13 & & $3,445^{\text {ns }}$ & & $2,426^{*}$ & & $2,157 * *$ & & $1,082^{\mathrm{ns}}$ \\
\hline Resíduo & 52 & & 2,644 & & 1,052 & & 0,616 & & 0,589 \\
\hline
\end{tabular}

${ }^{\text {ns }}$ não significativo; * Significativo a $5 \%$ de probabilidade; ** Significativo a $1 \%$ de probabilidade, pelo teste $\mathrm{F}$. ${ }^{1}$ valor multiplicado por $10^{3}$

A característica comprimento de vagem teve maior variação entre os genótipos, formando quatro classes diferentes em Cambé, de acordo com o teste de Scott-Knott (Tabela 2). Para as demais características, as médias de genótipos em cada local foram agrupadas entre uma a três classes. A produção de vagem variou entre 7,55 e 4,08 $\mathrm{t} \mathrm{ha}^{-1}$ em Londrina e de 10,07 a 5,02 t ha-1 em Cambé. As melhores médias gerais para produção $\left(7,3 \mathrm{t} \mathrm{ha}^{-1}\right)$, número de vagens por planta $(6,3)$ e comprimento de vagem $(14,7 \mathrm{~cm})$, foram registradas em Cambé, enquanto a melhor média para diâmetro de vagem (14,6 mm) foi observada em Londrina. Considerando que a interação genótipo $\mathrm{x}$ ambiente foi não significativa para produção de vagem, em média as linhagens UEL2, HAB 415 e HAB 441, Coralina e HAB 417 produziram 8,70; 8,10; 7,30 e $6,81 \mathrm{t} \mathrm{ha}^{-1}$, respectivamente As linhagens HAB
402, HAB 415, HAB 417 e HAB 441 destacaram-se por estarem presentes nos primeiros grupos, sendo competitivo com as melhores cultivares: UEL 2 e Coralina (Tabela 2). De acordo com a semelhança entre as medidas de diâmetro e largura da vagem, avaliados em Londrina, observa-se que a maioria das linhagens é cilíndrica (tipo macarrão), exceto HAB 447, HAB 448 e a cultivar Novirex. Com relação a cor do tegumento da semente, a cultivar Coralina é rajado marrom, a Novirex e HAB 429 são de cor preta e as demais têm cor branca.

$\mathrm{Na}$ análise de divergência genética, as oito características avaliadas foram representadas pelos três primeiros componentes principais e três primeiras variáveis canônicas, explicando uma variação total acumulada de $90,2 \%$ pelos componentes principais (Tabela 3 ) e $88,7 \%$ pelas variáveis canônicas (Tabela 4). 
Tabela 2. Médias dos genótipos de feijão-vagem e coeficiente de variação para produção de vagem (PV, em $t$ ha-1), número de vagens por planta $(\mathrm{NV})$, comprimento de vagem $(\mathrm{CV}$, em $\mathrm{cm})$, diâmetro de vagem (DV, em mm), largura de vagem ( $\mathrm{LV}, \mathrm{em} \mathrm{cm}$ ), número médio de sementes por vagem (NS), produção de sementes (PS, em kg ha ${ }^{-1}$ ) e porcentagem de casca na vagem seca (PC, em \%), obtidos em Londrina (Lo) e Cambé (Ca).

\begin{tabular}{|c|c|c|c|c|c|c|c|c|c|c|c|c|}
\hline \multirow[t]{2}{*}{ Genótipo } & \multicolumn{2}{|c|}{ PV } & \multicolumn{2}{|c|}{ NV } & \multicolumn{2}{|c|}{$\mathrm{CV}$} & \multicolumn{2}{|c|}{ DV } & \multirow{2}{*}{$\begin{array}{l}\text { LV } \\
\text { Lo }\end{array}$} & \multirow{2}{*}{\begin{tabular}{|l|} 
NS \\
Lo
\end{tabular}} & \multirow{2}{*}{$\begin{array}{l}\text { PS } \\
\text { Lo }\end{array}$} & \multirow{2}{*}{$\begin{array}{l}\text { PC } \\
\text { Lo }\end{array}$} \\
\hline & Lo & Ca & Lo & $\mathbf{C a}$ & Lo & Ca & Lo & Ca & & & & \\
\hline НАВ 402 & $6,35 \mathrm{a}$ & $6,10 \mathrm{~b}$ & $3,4 \mathrm{~b}$ & $4,8 \mathrm{a}$ & $13,5 \mathrm{a}$ & $15,5 \mathrm{~b}$ & $9,5 \mathrm{a}$ & $15,5 \mathrm{a}$ & $10,0 \mathrm{a}$ & $4,2 \mathrm{a}$ & $401,9 \mathrm{a}$ & $32,4 \mathrm{~b}$ \\
\hline HAB 415 & $6,82 \mathrm{a}$ & $9,38 \mathrm{a}$ & $4,4 \mathrm{a}$ & $7,1 \mathrm{a}$ & $13,7 \mathrm{a}$ & $16,1 \mathrm{~b}$ & $11,0 \mathrm{a}$ & $15,6 \mathrm{a}$ & $11,1 \mathrm{a}$ & $4,0 \mathrm{a}$ & $429,0 \mathrm{a}$ & $33,6 \mathrm{~b}$ \\
\hline НАВ 417 & $6,41 \mathrm{a}$ & $7,20 \mathrm{~b}$ & $3,7 \mathrm{~b}$ & $6,2 \mathrm{a}$ & $13,8 \mathrm{a}$ & $15,9 \mathrm{~b}$ & $10,6 \mathrm{a}$ & $15,0 \mathrm{a}$ & $10,9 \mathrm{a}$ & $3,5 \mathrm{~b}$ & $336,9 \mathrm{a}$ & $31,3 \mathrm{~b}$ \\
\hline НАВ 429 & $5,34 \mathrm{~b}$ & $6,16 \mathrm{~b}$ & $3,1 \mathrm{~b}$ & $5,8 \mathrm{a}$ & $12,4 \mathrm{a}$ & $17,1 \mathrm{a}$ & $8,4 \mathrm{~b}$ & $14,2 \mathrm{~b}$ & $8,8 \mathrm{~b}$ & $4,3 \mathrm{a}$ & 499,7 a & $31,4 \mathrm{~b}$ \\
\hline НАВ 430 & $3,73 \mathrm{~b}$ & $5,02 \mathrm{~b}$ & $2,3 \mathrm{~b}$ & $6,3 \mathrm{a}$ & $11,5 \mathrm{~b}$ & $14,1 \mathrm{c}$ & $9,7 \mathrm{a}$ & $14,1 \mathrm{~b}$ & $9,3 \mathrm{~b}$ & $3,8 \mathrm{~b}$ & $246,7 \mathrm{~b}$ & $33,9 \mathrm{~b}$ \\
\hline НАB 431 & $4,24 \mathrm{~b}$ & $6,78 \mathrm{~b}$ & $3,1 \mathrm{~b}$ & $6,1 \mathrm{a}$ & $12,5 \mathrm{a}$ & $15,0 \mathrm{~b}$ & $9,9 \mathrm{a}$ & $14,7 b$ & $9,8 \mathrm{a}$ & $3,5 \mathrm{~b}$ & $197,5 \mathrm{~b}$ & $28,8 \mathrm{c}$ \\
\hline НАВ 441 & $7,55 \mathrm{a}$ & $8,74 \mathrm{a}$ & $5,8 \mathrm{a}$ & $6,5 \mathrm{a}$ & $12,0 \mathrm{~b}$ & $14,1 \mathrm{c}$ & $8,2 \mathrm{~b}$ & $14,0 \mathrm{~b}$ & $8,3 \mathrm{~b}$ & $3,9 \mathrm{a}$ & $359,4 \mathrm{a}$ & $35,5 \mathrm{~b}$ \\
\hline НАB 444 & $5,19 \mathrm{~b}$ & $8,10 \mathrm{a}$ & $2,9 \mathrm{~b}$ & $6,9 \mathrm{a}$ & $13,1 \mathrm{a}$ & $17,1 \mathrm{a}$ & $9,0 \mathrm{a}$ & $14,5 b$ & $9,6 \mathrm{~b}$ & $2,5 \mathrm{c}$ & $181,1 \mathrm{~b}$ & $28,2 \mathrm{c}$ \\
\hline НАВ 447 & $5,74 \mathrm{a}$ & $6,08 \mathrm{~b}$ & $3,7 \mathrm{~b}$ & $5,7 \mathrm{a}$ & $10,7 \mathrm{~b}$ & $11,3 \mathrm{~d}$ & $7,4 \mathrm{~b}$ & $13,9 \mathrm{~b}$ & $8,7 \mathrm{~b}$ & $3,5 \mathrm{~b}$ & $372,6 \mathrm{a}$ & $33,5 \mathrm{~b}$ \\
\hline HAB 448 & $6,45 \mathrm{a}$ & $6,85 \mathrm{~b}$ & $5,7 \mathrm{a}$ & $6,4 \mathrm{a}$ & $11,1 \mathrm{~b}$ & $11,2 \mathrm{~d}$ & $7,2 \mathrm{~b}$ & $14,3 b$ & $8,7 \mathrm{~b}$ & $3,9 \mathrm{a}$ & $361,2 \mathrm{a}$ & $32,0 \mathrm{~b}$ \\
\hline НАВ 449 & $4,08 \mathrm{~b}$ & $7,11 \mathrm{~b}$ & $2,5 \mathrm{~b}$ & $6,4 \mathrm{a}$ & $10,8 \mathrm{~b}$ & $13,2 \mathrm{c}$ & $8,1 \mathrm{~b}$ & $13,8 \mathrm{~b}$ & $8,5 \mathrm{~b}$ & $3,3 \mathrm{~b}$ & $151,6 \mathrm{~b}$ & $28,9 \mathrm{c}$ \\
\hline Coralina & $4,58 \mathrm{~b}$ & $10,02 \mathrm{a}$ & $2,2 \mathrm{~b}$ & $7,1 \mathrm{a}$ & $12,2 \mathrm{a}$ & $15,6 \mathrm{~b}$ & $10,1 \mathrm{a}$ & $16,3 \mathrm{a}$ & $10,6 \mathrm{a}$ & $4,6 \mathrm{a}$ & 389,9 a & $27,9 \mathrm{c}$ \\
\hline Novirex & $4,27 \mathrm{~b}$ & $5,09 \mathrm{~b}$ & $2,5 \mathrm{~b}$ & $5,3 \mathrm{a}$ & $13,8 \mathrm{a}$ & $15,7 \mathrm{~b}$ & $7,8 \mathrm{~b}$ & $14,1 \mathrm{~b}$ & $9,4 \mathrm{~b}$ & $2,5 \mathrm{c}$ & $62,8 \mathrm{~b}$ & $44,2 \mathrm{a}$ \\
\hline UEL 2 & $7,33 \mathrm{a}$ & $10,07 \mathrm{a}$ & $5,4 \mathrm{a}$ & $7,1 \mathrm{a}$ & $12,4 \mathrm{a}$ & $13,8 \mathrm{c}$ & $10,4 \mathrm{a}$ & $14,7 \mathrm{a}$ & $10,5 \mathrm{a}$ & $4,0 \mathrm{a}$ & $380,9 \mathrm{a}$ & $24,9 \mathrm{c}$ \\
\hline M. Geral & 5,60 & 7,30 & 3,6 & 6,3 & 12,4 & 14,7 & 9,1 & 14,6 & 9,6 & 3,7 & 312,2 & 31,9 \\
\hline CV\% & 26,0 & 24,3 & 28,9 & 16,0 & 7,4 & 4,3 & 8,6 & 5,2 & 6,6 & 9,9 & 35,9 & 9,4 \\
\hline
\end{tabular}

Médias seguidas pela mesma letra, em cada coluna, pertencem a uma mesma classe, de acordo com o teste de Scott-Knott, em nível de $5 \%$ de probabilidade.

Tabela 3. Componentes principais $(\mathrm{CP})$ obtidos e variância acumulada (\%) e coeficientes de ponderação associado à produção de vagem $\left(\mathrm{PV}, \mathrm{em} \mathrm{t} \mathrm{ha}^{-1}\right)$, número de vagens por planta $(\mathrm{NV})$, comprimento de vagem $(\mathrm{CV}$, em cm), diâmetro de vagem $(\mathrm{DV}$, em $\mathrm{mm})$, largura de vagem $(\mathrm{LV}$, em $\mathrm{cm})$, número médio de sementes por vagem $(\mathrm{NS})$, produção de sementes (PS, em kg ha $\left.{ }^{-1}\right)$ e porcentagem de casca na vagem seca (PC, em \%) obtidos em Londrina, PR.

\begin{tabular}{|c|c|c|c|c|c|c|c|c|c|}
\hline \multirow{2}{*}{$\begin{array}{c}\text { Componentes } \\
\text { principais } \\
(\mathrm{CP})\end{array}$} & \multirow{2}{*}{$\begin{array}{c}\text { Variância } \\
\text { Acumulada (\%) }\end{array}$} & \multicolumn{8}{|c|}{ Coeficientes de ponderação associados a: } \\
\hline & & PV & NV & $\mathrm{CV}$ & DV & LV & NS & PS & $\mathrm{PC}$ \\
\hline $\mathrm{CP}_{1}$ & 43,84 & 0,40 & 0,31 & 0,05 & 0,313 & 0,22 & 0,112 & 0,48 & $-0,41$ \\
\hline $\mathrm{CP}_{2}$ & 72,84 & $-0,10$ & $-0,28$ & 0,56 & $\mathbf{0 , 4 7 3}$ & 0,56 & $-0,070$ & $-0,09$ & 024 \\
\hline $\mathrm{CP}_{3}$ & 90,15 & $\mathbf{0 , 5 4}$ & $\mathbf{0 , 5 5}$ & 0,36 & $-0,208$ & 0,01 & $-0,384$ & $-0,09$ & 029 \\
\hline $\mathrm{CP}_{4}$ & 90,71 & $-0,05$ & $-0,16$ & 0,35 & $-0,118$ & $-0,44$ & 0,333 & 052 & 052 \\
\hline $\mathrm{CP}_{5}$ & 97,44 & 0,17 & $-0,47$ & 0,35 & $-0,381$ & $-0,02$ & $-0,37$ & 028 & $-0,51$ \\
\hline $\mathrm{CP}_{6}$ & 98,74 & $-0,16$ & 0,06 & $-0,39$ & $-0,403$ & 0,62 & $-0,13$ & 046 & 028 \\
\hline $\mathrm{CP}_{7}$ & 99,84 & 0,233 & $-0,18$ & $-0,38$ & 0,541 & $-0,22$ & $-0,54$ & 034 & 016 \\
\hline $\mathrm{CP}_{8}$ & 100,00 & $-0,657$ & 0,49 & 0,25 & 0,148 & $-0,15$ & $-0,32$ & 027 & $-0,23$ \\
\hline
\end{tabular}


Tabela 4. Variáveis canônicas (VC) estabelecidas pela combinação linear das variáveis padronizadas e a variância acumulada (\%) e coeficientes de ponderação associado à produção de vagem (PV, em t ha ${ }^{-1}$ ), número de vagens por planta $(\mathrm{NV})$, comprimento de vagem $(\mathrm{CV}$, em cm), diâmetro de vagem (DV, em mm), largura de vagem (LV, em $\mathrm{cm})$, número médio de sementes por vagem (NS), produção de sementes (PS, em $\mathrm{kg} \mathrm{ha}^{-1}$ ) e porcentagem de casca na vagem seca (PC, em \%) obtidos em Londrina, PR.

\begin{tabular}{cccccccccc}
\hline Variáveis & Variância & \multicolumn{7}{c}{ Coeficientes de ponderação associado a: } \\
\cline { 2 - 10 } $\begin{array}{c}\text { canônicas } \\
\text { (VC) }\end{array}$ & Acumulada (\%) & $\mathrm{PV}$ & $\mathrm{NV}$ & $\mathrm{CV}$ & $\mathrm{DV}$ & $\mathrm{LV}$ & $\mathrm{NS}$ & $\mathrm{PS}$ & $\mathrm{PC}$ \\
\hline $\mathrm{VC}$ & 59,30 & $\mathbf{0 , 4 9}$ & $-1,96$ & $\mathbf{1 , 1 0}$ & $-1,29$ & $\mathbf{1 , 5 8}$ & $-0,25$ & $-0,40$ & $-0,07$ \\
$\mathrm{VC}_{2}$ & 79,19 & $-0,22$ & 0,02 & 0,08 & $\mathbf{0 , 1 7}$ & 0,71 & 0,52 & $\mathbf{0 , 0 9}$ & $-0,49$ \\
$\mathrm{VC}_{3}$ & 88,67 & $-1,15$ & $\mathbf{0 , 7 4}$ & $-0,06$ & $-0,07$ & 0,14 & $\mathbf{1 , 0 7}$ & 0,02 & $\mathbf{1 , 2 2}$ \\
$\mathrm{VC}_{4}$ & 93,66 & 0,15 & $-0,11$ & 0,99 & $-0,55$ & $-0,36$ & 0,13 & 0,40 & 0,44 \\
$\mathrm{VC}_{5}$ & 97,72 & $-1,11$ & 1,32 & 0,02 & $-0,32$ & 0,67 & $-0,89$ & $-0,23$ & $-0,04$ \\
$\mathrm{VC}_{6}$ & 99,07 & 0,66 & $-0,11$ & $-0,02$ & 1,09 & $-0,56$ & $-0,02$ & $-0,56$ & 0,03 \\
$\mathrm{VC}_{7}$ & 99,81 & 0,27 & $-0,14$ & $-0,53$ & 0,36 & 0,12 & $-0,37$ & 0,61 & 0,31 \\
$\mathrm{VC}_{8}$ & 100,0 & $\mathbf{1 , 3 1}$ & $-0,69$ & $-0,37$ & $-0,32$ & 0,22 & 0,35 & $-0,44$ & 0,28 \\
\hline
\end{tabular}

Iezzoni e Pritts (1991), afirmam que, geralmente, descritores com maiores autovetores e maiores coeficientes de correlação são considerados de maior importância para o respectivo componente. Neste sentido, no primeiro componente principal, os caracteres de maior contribuição na discriminação dos genótipos foram: número de sementes por vagem e produção de sementes. No segundo componente, destacaram-se comprimento, diâmetro e largura de vagem; e no terceiro, os caracteres produção e número de vagens por planta e porcentagem de casca (Tabela 3). Os caracteres de maior contribuição na discriminação dos genótipos nas três variáveis canônicas foram: produção, comprimento e largura de vagem na primeira variável canônica; diâmetro de vagem e produção de sementes na segunda variável e número de vagens por planta, número de sementes por vagem e porcentagem de casca na terceira variável (Tabela 4). A partir da análise dos caracteres nos três componentes principais podese observar que as características morfológicas de vagens e produção de sementes estão agrupadas nos dois primeiros componentes e as características relacionadas à produção de vagens estão agrupadas no terceiro componente principal. Essa associação não foi observada para variáveis canônicas que levam em consideração as matrizes de covariância residual e fenotípica entre os caracteres.

Observou-se que produção de vagens foi a variável de menor importância relativa entre os caracteres na análise de componentes principais e também nas variáveis canônicas (Tabela 3 e 4), sendo este resultado também observado por Abreu et al.(2004). No trabalho de Peixoto et al. (2002), o peso médio de vagem contribuiu com 3,28\% para a divergência entre os genótipos de feijãovagem de crescimento indeterminado. Caracteres dispensáveis em estudos de divergência são aqueles que relativamente não variam entre as cultivares estudadas e, ou, são redundantes por estarem correlacionadas com outros caracteres (CRUZ; REGAZZI, 2001).

Os escores das linhagens e cultivares de feijãovagem em relação aos três primeiros componentes principais e variáveis canônicas (Tabela 5) facilitam a tarefa de selecionar genótipos com características específicas. Os genótipos que tiveram maiores coeficientes nas três colunas dos componentes principais e variáveis canônicas são os mais indicados para seleção de genótipos mais adaptados.

Na primeira coluna $\left(\mathrm{CP}_{1}\right)$ as linhagens indicadas foram HAB 402, HAB 415, HAB 417, HAB 429, HAB 441, HAB 448 e as cultivares Coralina e UEL2. Na coluna do segundo componente $\left(\mathrm{CP}_{2}\right)$, representado pelo caráter comprimento de vagem, os genótipos mais indicados foram $\mathrm{HAB} 402, \mathrm{HAB}$ 415, HAB 417, HAB 444, 'Coralina' e 'Novirex'. 
Para produção de vagem e número de vagens por planta $\left(\mathrm{CP}_{3}\right)$ foram $\mathrm{HAB} 402$, HAB 415 , HAB 417 , HAB 441, HAB 444, HAB 448, Novirex e UEL2. Os genótipos com os melhores escores nos três eixos foram HAB 402, HAB 415 e HAB 417, associando produção de vagem e boa produção de sementes. As cultivares Novirex, UEL e Coralina apresentaram menores escores no primeiro (características morfológicas da vagem e produção de sementes), segundo (comprimento de vagem) e terceiro eixo (produção de vagem e número de vagens por planta), respectivamente (Tabela 5).
Na primeira coluna $\left(\mathrm{VC}_{1}\right)$ as linhagens indicadas foram HAB 402, НАB 415, НAB 417, НAB 430, HAB 331, HAB 444 e as cultivares Coralina e Novirex. Na coluna do segundo componente $\left(\mathrm{VC}_{2}\right)$, os genótipos mais indicados foram HAB 402, HAB 415, HAB 417, НAB 429, НAB 430, НAB 431, 'Coralina' e 'UEL2'. Para a terceira coluna $\left(\mathrm{CP}_{3}\right)$ foram HAB 415, HAB 417, HAB 430, HAB 431, 'Coralina' e 'Novirex'. Na tabela 5, os genótipos com os melhores escores nos três eixos foram HAB 415, HAB 417, HAB 430 e HAB 431. Contudo deve-se observar que as linhagens HAB 402, HAB 415 e HAB 417 tiveram os melhores escores em todas as colunas ( $\mathrm{CP}$ e $\mathrm{VC})$.

Tabela 5. Escores obtidos para as 11 linhagens HAB e três cultivares de feijão-vagem, em relação aos três primeiros componentes principais $\left(\mathrm{CP}_{1}, \mathrm{CP}_{2}\right.$ e $\left.\mathrm{CP}_{3}\right)$ e três primeiras variáveis canônicas $\left(\mathrm{CV}_{1}, \mathrm{CV}_{2}\right.$ e $\left.\mathrm{CV}_{3}\right)$ avaliados em Londrina, PR.

\begin{tabular}{|c|c|c|c|c|c|c|}
\hline \multirow[b]{2}{*}{ Genótipos } & \multicolumn{3}{|c|}{ Componentes principais } & \multicolumn{3}{|c|}{ Variáveis canônicas } \\
\hline & $\mathrm{CP}_{1}$ & $\mathrm{CP}_{2}$ & $\mathrm{CP}_{3}$ & $\mathrm{VC}_{1}$ & $\mathrm{VC}_{2}$ & $\mathrm{VC}_{3}$ \\
\hline HAB 402 & 14,33 & 22,42 & 3,23 & 5,66 & 16,40 & 20,81 \\
\hline HAB 415 & 14,70 & 23,16 & 4,23 & 6,49 & 16,73 & 22,13 \\
\hline HAB 417 & 13,30 & 23,08 & 4,42 & 8,76 & 15,45 & 21,04 \\
\hline НАВ 429 & 13,34 & 20,54 & 2,68 & 3,22 & 14,71 & 22,66 \\
\hline HAB 430 & 11,26 & 20,77 & 1,92 & 5,70 & 14,36 & 22,04 \\
\hline HAB 431 & 11,44 & 21,97 & 3,021 & 6,04 & 14,22 & 22,38 \\
\hline НАВ 441 & 13,84 & 19,11 & 4,95 & $-1,63$ & 13,46 & 20,57 \\
\hline НАB 444 & 10,62 & 22,22 & 4,33 & 8,23 & 12,14 & 19,04 \\
\hline НАВ 447 & 12,59 & 19,24 & 3,03 & 1,61 & 13,62 & 19,32 \\
\hline НАB 448 & 13,25 & 19,38 & 4,33 & $-2,56$ & 13,34 & 23,50 \\
\hline НАВ 449 & 10,32 & 19,83 & 2,45 & 3,82 & 12,47 & 20,65 \\
\hline Coralina & 14,29 & 22,92 & 1,01 & 5,47 & 18,17 & 22,44 \\
\hline Novirex & 8,85 & 22,88 & 4,73 & 9,86 & 10,62 & 23,13 \\
\hline UEL2 & 15,05 & 20,96 & 4,29 & 3,54 & 16,91 & 19,52 \\
\hline
\end{tabular}

Os dendrogramas (Figura 1) baseados nas distâncias euclidianas a partir dos escores dos três principais componentes principais (DCP) e variáveis canônicas (DVC) separou os genótipos em cinco (I, II, III, IV e V) e sete grupos (1, 2, 3, 4, 5 , e 6) respectivamente. O grupo I do DCP formado pelas linhagens HAB 441, HAB 448 e por 'UEL 2' separou-se em diferentes grupos no DVC. O grupo II do DCP formado pelas linhagens HAB 415, HAB 417 e HAB 402 permaneceram juntos no DVC juntando-se a este grupo a cultivar Coralina do grupo
V do DCP. O grupo III (DCP) formado por cinco linhagens separou-se em dois grupos no DVC: grupo 1 (HAB 430, HAB 431 e HAB 429) e grupo 4, onde as linhagens HAB 447 e HAB 449 juntaram-se com as linhagens HAB 441(grupo I) e HAB 444 (grupo IV). Apesar de a variabilidade disponível ter-se distribuído de maneira semelhante, o agrupamento em relação aos escores das variáveis canônicas, apresentou diferenças diante do encontrado com o uso dos componentes principais. Segundo Cruz e Regazzi (2001) o grau de concordância entre 
componentes principais e variáveis canônicas, é dependente da magnitude das correlações residuais que podem existir dentre os caracteres considerados, contudo ambas as técnicas apresentam certa robustez de forma que suas aplicações poderão proporcionar resultados satisfatórios e de grande utilidade para o melhoramento, mesmo havendo correlação residual entre os caracteres avaliados.

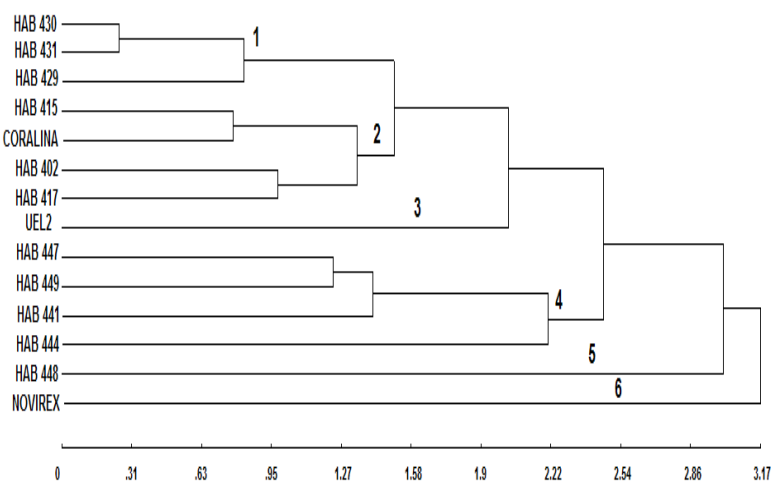

(b) (a)

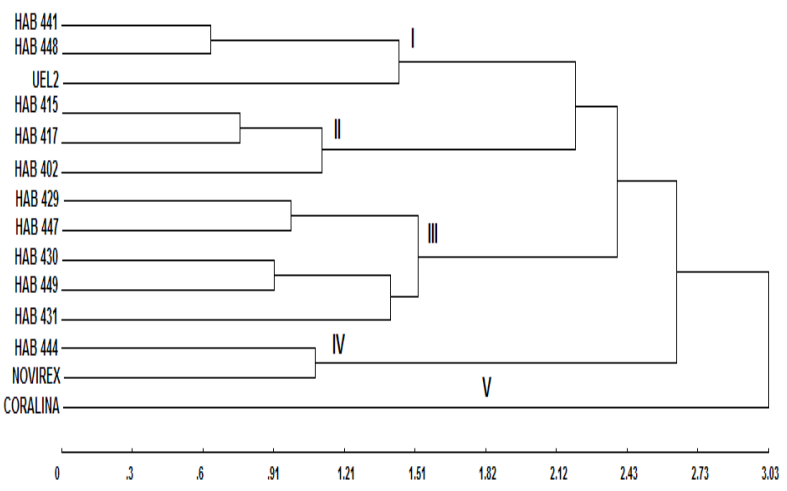

Figura 1. Dendrogramas de 11 linhagens HAB e três cultivares de feijão-vagem, baseado nas distâncias Euclidianas, a partir dos escores obtidos dos três primeiros componentes principais (a) e três primeiras variáveis canônicas (b)

As melhores linhagens, HAB 402, HAB 415 e HAB 417, de acordo com o critério de médias de Scott-Knott e a análise de componentes principais e variáveis canônicas estão no mesmo grupo II e 2, respectivamente, demonstrando que são similares e podem ser recomendadas para cultivo em Londrina e Cambé, sendo também dissimilares em relação às cultivares testadas.

De acordo com Maluf e Ferreira (1983), Cruz e Regazzi, (2001), Emygdio et al., (2003) e Abreu et al., (2004), a recomendação de cruzamentos em programas de melhoramento, depende da utilização de genitores com maior divergência possível para maximizar a probabilidade de ocorrência de segregantes superiores em gerações avançadas e ampliar a base genética, levando também em consideração o comportamento per se, ou seja, genótipos que apresentem desempenho superior nas principais características de importânciaagronômica. Nesse sentido, observou-se que as cultivares estão representadas em agrupamentos diferentes e podem ser cruzadas com as melhores linhagens (HAB 402, НAB 415, HAB 417, НAB 441, HAB 444e
HAB 448), assim como se tem a possibilidade de cruzamentos entre estas linhagens que sejam divergentes para obter gerações segregantes com potencial heterótico.

\section{Conclusões}

As linhagens de feijão-vagem tiveram bom desempenho agronômico e formaram grupos de dissimilaridade, e podem ser usadas em programas de melhoramento. As linhagens mais promissoras, HAB 402, HAB 415 e HAB 417, pertencem ao mesmo grupo e são dissimilares em relação às cultivares testadas. Foi verificado certo grau de concordância entre componentes principais e canônicas, que representaram mais de $88 \%$ da

\section{Agradecimentos}

Agradecemos ao Pesquisador Dr. Michael D. T. Thung da Embrapa - Arroz e Feijão, pelo fornecimento das linhagens, e à Fundação Araucária, pelo apoio financeiro. variabilidade total disponível. 


\section{Referências}

ABREU, F. B.; LEAL N. R.; RODRIGUES. R.; AMARAL JUNIOR, A. T.; SILVA, D. J. H. Divergência genética entre acessos de feijão-de-vagem de hábito de crescimento indeterminado. Horticultura Brasileira, Brasília, v. 22, n. 3, p. 547-552, 2004.

ATHANÁZIO, J. C.; TAKAHASHI, L. S. A.; ENDO, R. M.; SILVA, G. L. UEL-2: cultivar de feijão-de-vagem tipo manteiga de crescimento determinado. Horticultura Brasileira, Brasília, v. 16, n. 1, p. 91, 1998.

BLANCO, M. C. S. G.; GROPPO, G. A.;TESSARIOLI NETO, J. Feijão-de-vagem (Phaseolus vulgaris L.). Manual Técnico das Culturas, Campinas, n. 8, p. 63-65, 1997.

BRANDÃO, R. A. P. Avaliação da qualidade das vagens e sementes de feijão-vagem (Phaseolus vulgaris L.), cvs. UEL-1 e AG-274, em função da idade e época de cultivo. 2001. Tese (Mestrado em Agronomia) - Universidade Estadual de Londrina, Londrina.

CASTELLANE, P. D.; VIEIRA, R. F.; CARVALHO, N. M. Feijão-de-vagem (Phaseolus vulgaris L.): cultivo e produção de sementes. Jaboticabal: FUNEP/FCAVUNESP. 1988. 60 p.

CORREIA, A. R.; GODOI, H.; BERNARDES, L. R. M. Características climáticas de Londrina. 2. ed. Londrina: IAPAR, 1982. (Circular, n. 5).

CRUZ, C. D. Programa genes: biometria. Viçosa: UFV, 2006.

CRUZ, C. D.; REGAZZI, A. J. Modelos biométricos aplicados ao melhoramento genético. Imprensa Universitária, Viçosa, MG, 2001. 390 p.

EMYGDIO, B. M; ANTUNES, I. F; NEDEL, J. L; CHOER, E. Diversidade genética em cultivares locais e comerciais de feijão baseadas em marcadores RAPD. Pesquisa Agropecuária Brasileira, Brasília, v. 38, n. 10, p. 1165-1171, out. 2003.

FILGUEIRA, F. A. R. Novo manual de olericultura: agrotecnologia moderna na produção e comercialização de hortaliças. 3 ed. Viçosa: Universidade Federal de Viçosa, 2003. 412 p.

FONSECA, J. R.; SILVA, H. T. Identificação de duplicidade de acessos de feijão por meio de técnicas multivariadas. Pesquisa Agropecuária Brasileira, Brasília, v. 34, n. 3, p. 409-414, 1999.

IEZZONI, A.; F.;PRITTS, M. P. Applications of principal component analysis to horticultural research. HortScience, Alexandria, v. 26, n. 4, p. 334-338, 1991.
MALUF, W. R.; FERREIRA, P. E. Análise multivariada da divergência genética em feijão-de-vagem (Phaseolus vulgaris L.). Horticultura Brasileira, Brasília, v. 1, n. 2, p. 31-34. 1983.

PEIXOTO, N.; THUNG, M. D. T.; SILVA, L. O.; FARIAS, J. G.; OLIVEIRA, E. B.; BARBEDO, A. S. C.; SANTOS, G. Produção de sementes de linhagens e cultivares arbustivas de feijão-de-vagem em AnápolisGO. Horticultura Brasileira, Brasília, v. 11, n. 2, p. 151$152,1993$.

Avaliação de cultivares arbustivas de feijãovagem, em diferentes ambientes do Estado de Goiás. Boletim de Pesquisa, Goiânia: EMATER-GO, 1997. 20 p. (Boletim Técnico).

PEIXOTO, N.;BRAZ, L. T.; BANZATTO, D. A., MORAES, E. A., MOREIRA, F. M. Características agronômicas, produtividade, qualidade de vagens e divergência genética em feijão-vagem de crescimento indeterminado. Horticultura Brasileira, Brasília, v. 20, n. 3, p. 447-451, 2002.

PINTO, C. M. F.; VIEIRA, R. F.; VIEIRA, C.; CALDAS, M. T. Insumos e cultivares em teste : idade de colheita do feijão-vagem anão cultivar novirex. Horticultura Brasileira, Brasília, v 19, n. 2, p. 163-167, Jul. 2001.

RODRIGUES, R.; LEAL, N. R.; PEREIRA, M. G. Análise dialélica de seis características agronômicas em Phaseolus vulgaris L. Bragantia, Campinas, v. 57, n. 2, p. 241-250, 1998.

SILVA, K., MENEGUCE, B., MARTINELLI, A. P.; CAMOLESI, M. R.;FERREIRA, J.M.; MOREIRA, R. M. P.; TAKAHASHI, L. S.; THUNG, M. D. T.; CARNEIRO, G. E. S. Caracterização de linhagens de feijão-vagem de crescimento determinado In: V MOSTRA ACADÊMICA DE TRABALHOS DE AGRONOMIA. Londrina: UEL, 2001.

SILVA, M. P.; AMARAL JÚNIOR, A. T.; PEREIRA, M. G.; RODRIGUES, R.; DAHER, R. F.; POSSE, S. C. P. Diversidade genética e identificação de híbridos por marcadores RAPD em feijão-de-vagem. Acta Scientiarum Agronomy, Maringá, v. 27, n. 3, p. 531-539, 2005.

TEIXEIRA, A. B.; AMARAL JÚNIOR, A. T; RODRIGUES, R.; PEREIRA, T. N. S.; BRESSANSMITH, R. E. Genetic divergence in snap-bean (Phaseolus vulgaris L.) evaluated by different methodologies. Crop Breending and Applied Biotechnology, Viçosa, v. 4, n. 1, p. 57-62, 2004.

VENCOVSKY, R.; BARRIGA, P. Genética biométrica no fitomelhoramento. Ribeirão Preto: Sociedade Brasileira de Genética, 1992. 496 p. 